\title{
A randomised controlled trial of an active telephone-based recruitment strategy to increase childcare-service staff attendance at a physical activity and nutrition training workshop
}

\author{
Sze Lin Yoong ${ }^{\mathrm{A}, \mathrm{C}}$, Luke Wolfenden ${ }^{\mathrm{A}, \mathrm{B}}$, Meghan Finch ${ }^{\mathrm{A}, \mathrm{B}}$, Amanda Williams $^{\mathrm{A}}$, Pennie Dodds ${ }^{\mathrm{A}}$, \\ Karen Gillham ${ }^{\mathrm{B}}$ and Rebecca Wyse $\mathrm{A}^{\mathrm{B}}$ \\ ASchool of Medicine and Public Health, Faculty of Health, University of Newcastle, Callaghan, NSW 2308, Australia. \\ BHunter New England Population Health, Hunter New England Health District, Booth Building, Longworth Avenue, \\ Wallsend, NSW 2287, Australia. \\ CCorresponding author. Email: serene.yoong@hnehealth.nsw.gov.au
}

\begin{abstract}
Issue addressed: Centre-based childcare services represent a promising setting to target the prevention of excessive weight gain in preschool-aged children. Staff training is a key component of multi-strategy interventions to improve implementation of effective physical activity and nutrition promoting practices for obesity prevention in childcare services. This randomised controlled trial aimed to examine whether an active telephone-based strategy to invite childcare-service staff to attend a training workshop was effective in increasing the proportion of services with staff attending training, compared with a passive strategy.

Methods: Services were randomised to an active telephone-based or a passive-recruitment strategy. Those in the active arm received an email invitation and one to three follow-up phone calls, whereas services in the passive arm were informed of the availability of training only via newsletters. The proportion of services with staff attending the training workshop was compared between the two arms.

Results: One hundred and twenty-eight services were included in this study. A significantly larger proportion (52\%) of services in the active arm compared with those in the passive-strategy arm (3.1\%) attended training $\left(\mathrm{d} . \mathrm{f} .=1, \chi_{2}=34.3 ; P<0.001\right)$.

Conclusions: An active, telephone-based recruitment strategy significantly increased the proportion of childcare services with staff attending training. Further strategies to improve staff attendance at training need to be identified and implemented.
\end{abstract}

So what? Active-recruitment strategies including follow-up telephone calls should be utilised to invite staff to participate in training, in order to maximise the use of training as an implementation strategy for obesity prevention in childcare services.

Key words: capacity building, child care, obesity.

Received 5 July 2013, accepted 8 October 2013, published online 19 December 2013

\section{Introduction}

The prevention of obesity in children represents a recommended strategy for reducing the overall burden of disease attributed to obesity in the community. ${ }^{1}$ Childcare services provide an attractive setting for interventions to reduce population prevalence of excessive weight gain, ${ }^{2}$ given the large proportion of children that attend such services annually. ${ }^{3}$ Although research has identified some effective obesity-prevention programs, ${ }^{4}$ population-wide implementation of these initiatives in childcare services needs to occur to achieve public-health benefits.
Staff lack of knowledge, skills and confidence are frequently reported barriers to the implementation of obesity-prevention initiatives in childcare settings. 5,6 Thus, the provision of staff training in nutrition and physical activity represents a key strategy to support implementation of obesity-prevention programs.

A range of passive and active strategies have been used to invite staff to attend training. ${ }^{7-9}$ Passive strategies involve general invitations via newsletters, posters or mass media, where participants are required to respond to these invitations on their own initiative. 
In contrast, active strategies are recruiter-driven and involve mail or telephone-based invitations.

Despite the variety of recruitment methods used and the potential costs associated with these strategies, it is largely unknown how effective these strategies are in improving childcare staff attendance at training. To inform the implementation of large-scale obesityprevention initiatives and support services in their delivery of nutrition and physical activity promoting practices, we conducted a trial to assess the effectiveness of an active strategy in increasing the proportion of childcare services with staff attending training, compared with a passive strategy.

\section{Methods}

This trial was conducted as part of a regional child-obesity-prevention initiative offered to all childcare services located within a government-defined health district. These services were previously offered training in nutrition in 2007 and physical activity in 2009.?

\section{Study design}

The study was a randomised controlled trial. Allocation of services was carried out centrally using the RAND function in Microsoft Excel.

\section{Eligibility criteria}

Service information obtained from a routine telephone interview conducted with supervisors from childcare services in the Hunter and New England area was used to determine eligibility to participate in this trial. As training was conducted in the Hunter region, only services within this region were invited to participate. Non-government services, services not catering exclusively for a special needs population and not providing all main meals were eligible to participate.

\section{Training}

The Munch and Move workshop is a government-funded 1-day workshop, available to all childcare services in NSW. This workshop consists of a 6-hour training and education session, focussing on supporting staff in the implementation of healthy eating and physical activity promoting policies and practices. Four 1-day training sessions were conducted between February and March 2013 in four locations within the Hunter area.

\section{Recruitment strategy}

\section{Passive recruitment}

In May 2012, childcare services received a newsletter indicating that they could access Munch and Move training delivered in their local area. Additional information regarding training dates, locations and contact person were available on the NSW Healthy Kids website. ${ }^{10}$

\section{Active recruitment}

We aimed to recruit $100 \%$ of services to training in the active arm of the study. In addition to receiving a newsletter, these services received a personalised email inviting them to register for training. One to three follow-up telephone calls were made by health-service staff to those who had not responded within 2 weeks. During these calls, staff checked whether supervisors had received the information and offered to resend information if needed. Childcare supervisors could register staff attendance directly over the phone. This occurred across a 6-week period.

\section{Outcomes}

\section{Service characteristics}

Service size (number of children enrolled) and operational characteristics (opening hours, opening days, number of primary contact staff) was obtained by telephone survey with supervisors of childcare services between August and September 2012. Distances to training location were obtained by calculating the distance from services to all training sites and using the minimum distance.

\section{Attendance at training}

Staff were required to sign in on the day of training and attendance was defined as at least one staff member attending training.

\section{Ethical approval}

Ethical approval was obtained from Hunter New England Human Research Ethics Committee (HNEHREC 12/08/15/5.01).

\section{Statistical analysis}

Statistical analyses were conducted using STATA 11.0.11 Descriptive statistics were used to describe service characteristics. The proportion attending training in both arms was compared using Pearson's Chisquare test.

\section{Results}

Of the 195 eligible services, 128 (66\% consent rate) were randomised to either the active $(n=64)$ or passive $(n=64)$ arm. No significant difference in service characteristics was identified between the two groups (Table 1).

A greater proportion of those in the active group $(n=33,52 \%)$ attended training compared with the passive group $(n=2,3.1 \%)$. This was significantly different between the two groups (d.f. $=1, \chi_{2}=34.3$; $P<0.001)$.

\section{Discussion}

Despite being a recommended strategy to support implementation of obesity-prevention programs into community settings, ${ }^{12}$ there

Table 1. Service characteristics of childcare services in the active and passive recruitment arms $(n=128)$

\begin{tabular}{lccc}
\hline Characteristics & $\begin{array}{c}\text { Active } \\
\text { mean (s.d.) }\end{array}$ & $\begin{array}{c}\text { Passive } \\
\text { mean (s.d.) }\end{array}$ & $\begin{array}{c}\boldsymbol{P} \text {-value } \\
\text { mean (s.d.) }\end{array}$ \\
\hline Operational hours per day & $7.9(0.1)$ & $8.0(0.08)$ & 0.79 \\
Days open per week & $4.9(0.05)$ & $4.9(0.04)$ & 0.46 \\
Primary contact staff per day & $7.3(5.0)$ & $8.6(5.8)$ & 0.07 \\
Number of children enrolled & $78(4.6)$ & $84(5.3)$ & 0.38 \\
Distance of service site to & $39(5.8)$ & $43(6.7)$ & 0.66 \\
training sites in kilometres & & & \\
\hline
\end{tabular}


has been little rigorous research identifying ways to improve staff training attendance. Several barriers to attending training have been reported, including distance needed to travel to access training, difficulties with back-filling the position of staff attending training, and reduced organisation support. ${ }^{13,14}$

While not directly addressing these barriers, findings from this trial indicate that active recruitment significantly increased the proportion of services with staff attending training. Approximately $50 \%$ of staff in the active arm attended training, comparable with that identified in trials examining the use of active telephonerecruitment strategies to increase use of other community services (38-67\%). ${ }^{15-18}$ Although effective, almost half of the services in the active arm did not have any staff attend training. This could have been due to the brief invitation period, the limited number of sessions offered and the scheduling of training at the beginning of the year, which coincided with centre reopening after end-of-year holidays.

In addition to active recruitment, strategies to address reported barriers to training could provide a means to further improve staff attendance. Baden and colleagues provided a stipend for teachers attending a smoking-cessation workshop and reported that almost all teachers attended the face-to-face training (98\%). ${ }^{9}$ Preschool supervisors express a preference for delivery of training on premises or outside working hours, ${ }^{8}$ which could help overcome barriers including travel to training sites and the need to back-fill staff. Other potentially useful strategies may include incorporating training sessions as part of staff annual professional development, staff meetings or reward schemes. ${ }^{14}$ Additionally, the inclusion of staff training in physical activity and nutrition as a mandatory component of childcare-service-accreditation processes (for example, as a quality standard in the National Quality Framework) may be necessary to ensure that this setting can be best used for obesity prevention.

\section{Limitations}

The research team have had previous contacts with services, which may have affected services' willingness to attend. The trial included only one active arm, thus it is unknown which component of the multi-stage recruitment (including email and telephone) was most effective in increasing attendance. We did not assess reasons for nonparticipation and cost of the active-recruitment strategy. However, as only up to three brief calls were made, we anticipate that cost of implementing this strategy would be relatively low.

\section{Conclusion}

An active-recruitment method significantly improved staff attendance at training compared with a passive strategy. Other strategies to improve staff training attendance need to be identified and implemented for training to be effectively used to build staff capacity to implement obesity-prevention programs.

\section{Acknowledgements}

This work was supported by funding from the Australian National Preventive Health Agency. The project also received infrastructure support from the Hunter Medical Research Institute (HMRI) and Hunter New England Population Health.

\section{References}

1. Lobstein T, Baur L, Uauy R. Obesity in children and young people: a crisis in public health. Obes Rev 2004; 5: 4-104. doi:10.1111/j.1467-789X.2004.00133.x

2. Larson N, Ward DS, Neelon SB, Story M. What role can child-care settings play in obesity prevention? A review of the evidence and call for research efforts. J Am Diet Assoc 2011; 111(9): 1343-62. doi:10.1016/j.jada.2011.06.007

3. Department of Education. Employment and Workplace Relations. National Preschool Census 2010: Aboriginal and Torres Strait Islanders and All Students; 2011. Available from: http://foi.deewr.gov.au/system/files/doc/other/national_preschool_census_2010_0.pdf [Accessed 15 May 2013]

4. Waters E, de Silva-Sanigorski A, Hall Belinda J, Brown T, Campbell Karen J, Gao Y. Interventions for preventing obesity in children. Cochrane Database Syst Rev doi:10.1002/14651858.CD001871.pub3

5. Fees B, Trost S, Bopp M, Dzewaltowski DA. Physical activity programming in family child care homes: providers' perceptions of practices and barriers. J Nutr Educ Behav 2009; 41(4): 268-73. doi:10.1016/j.jneb.2008.01.013

6. Sellers K, Russo TJ, Baker I, Dennison BA. The role of childcare providers in the prevention of childhood overweight. J Child Res 2005; 3(3): 227-42. doi:10.1177/ 1476718 X05056516

7. Finch M, Wolfenden L, Falkiner M, Edenden D, Pond N, Hardy LL, Milat AJ, Wiggers J. Impact of a population based intervention to increase the adoption of multiple physical activity practices in centre based childcare services: a quasi experimental, effectiveness study. Int J Behav Nutr Phys Act 2012; 9(1): 101. doi:10.1186/1479-58689-101

8. Jennings A, McEvoy S, Corish C. Nutritional practices in full-day-care pre-schools. $J$ Hum Nutr Diet 2011; 24(3): 245-59. doi:10.1111/j.1365-277X.2011.01153.x

9. Basen-Engquist K, O'Hara-Tompkins N, Lovato CY, Lewis MJ, Parcel GS, Gingiss P. The effect of two types of teacher training on implementation of Smart Choices: a tobacco prevention curriculum. J Sch Health 1994; 64(8): 334-9. doi:10.1111/j.17461561.1994.tb03323.x

10. New South Wales Deparment of Health. About Munch and Move. Available from: http://www.healthykids.nsw.gov.au/campaigns-programs/about-munch-move aspx [Verified 13 May 2013]

11. StataCorp. Stata Statistical Software: Release 11. College Station, TX: Stata Corp LP; 2009

12. Rabin BA, Glasgow RE, Kerner JF, Klump MP, Brownson RC. Dissemination and implementation research on community-based cancer prevention: a systematic review. Am J Prev Med 2010; 38(4): 443-56. doi:10.1016/j.amepre.2009.12.035

13. Hughes CC, Gooze RA, Finkelstein DM, Whitaker RC. Barriers to obesity prevention in Head Start. Health Aff 2010; 29(3): 454-62. doi:10.1377/hlthaff.2009.0499

14. Pollard C, Lewis J, Miller M. Start right-eat right award scheme: implementing food and nutrition policy in child care centers. Health Educ Behav 2001; 28(3): 320-30. doi:10.1177/109019810102800306

15. Tzelepis F, Paul CL, Walsh RA, Wiggers J, Knight J, Lecathelinais C, Daly J, Neil A, Girgis A. Telephone recruitment into a randomized controlled trial of quitline support. Am J Prev Med 2009; 37(4): 324-9. doi:10.1016/j.amepre.2009.05.022

16. Wolfenden L, Wiggers J, Campbell E, Knight J, Kerridge R, Moore K, Spigelman A, Harrison M. Feasibility, acceptability, and cost of referring surgical patients for postdischarge cessation support from a quitline. Nicotine Tob Res 2008; 10(6): 1105-8. doi:10.1080/14622200802097472

17. Lando HA, Hellerstedt WL, Pirie PL, McGovern PG. Brief supportive telephone outreach as a recruitment and intervention strategy for smoking cessation. Am J Public Health 1992; 82(1): 41-6. doi:10.2105/AJPH.82.1.41

18. Abdullah ASM, Mak YW, Loke AY, Lam TH. Smoking cessation intervention in parents of young children: a randomised controlled trial. Addiction 2005; 100(11): 1731-40. doi:10.1111/j.1360-0443.2005.01231.x 